\title{
Tooth Loss, Chewing Ability and Quality of Life
}

\section{Marcelo Carlos Bortoluzzi ${ }^{1 *}$, Jefferson Traebert ${ }^{2}$, Renata Lasta ${ }^{3}$, Thaiany Naila da Rosa ${ }^{3}$ and Diogo Lenzi Capella}

${ }^{1}$ School of Dentistry, Health Bioscience Postgraduate Program, Tissue Aspects for Health Prognosis and Intervention Laboratory (LAPROG), University of the West of Santa Catarina, Brazil, South America

${ }^{2}$ Public Dental Health Research Group, University of the West of Santa Catarina, Tubarao, Brazil

${ }^{3}$ University of the West of Santa Catarina, Brazil

\begin{abstract}
Objectives: The aim of this study was to observe the tooth loss over age in a sample of Brazilian patients and analyze their ability to chew, relating it to how much the lost of oral function impact over quality of life (QoL).
\end{abstract}

Materials and methods: This is a single center, observational study and the data were collected through clinical examination followed of questionnaires to obtain socio demographic information, the ability to chew (through the index of chewing ability - ICA) and QoL (through Oral Health Impact Profile, OHIP-14).

Results: The sample was composed of 171 random volunteers with mean age of 47 (SD 15.2). Low number of natural teeth was associated with increase in age (Spearman's rho correlation coefficient $-.7, \mathrm{P}<.001,2$-tailed) and chew disability (ICA: chew's ability versus disability) (Mann-Whitney U-Test, $\mathrm{P}<.001$ ). Chew disability showed a negative impact over the QoL (overall OHIP; Mann-Whitney U Test $\mathrm{P}<.001$ ) and in 5 of 7 OHIP domains (Functional Limitation, Physical Pain, Psychological Discomfort, Physical Disability, Psychological Disability). Age over than 40 years, was also associated with chewing disability (Pearson Chi-Square $\mathrm{P}<.001$ ) and poorer quality of life (MannWhitney $U$ test $P=.01$ ).

Conclusion: This study observed that the chewing disability produce a significant and negative impact over oralhealth related quality of life and both, poor quality of life and chewing disability are related with the decrease of the number of natural teeth.

Keywords: Quality of life; Chew's ability; Tooth loss; Oral healthrelated quality of life; Oral health impact profile (OHIP-14)

\section{Introduction}

The World Health Organization (WHO) [1] has defined Quality of Life (QoL) as "an individual's perception of their position in life in the context of the culture and value systems in which they live and in relation to their goals, expectations, standards and concerns". It is increasingly recognized that clinical indicators alone are not sufficient to describe health status and this is also true for oral diseases. Therefore, models and measures have been developed to assess the impact of oral disease on QoL [2-4].

Tooth loss implies loss of several orofacial structures, such as bone tissues, nerves, receptors and muscles and consequently, most orofacial functions are diminished. Studies have indicated that the decrease of number of teeth and for complete denture wearers the chew's ability is significantly less efficient and this may have consequences over general health and QoL of those patients. The negative impact on oral healthrelated quality of life (OHRQoL) may also be due to poor speech, pain, and dissatisfaction with appearance [4-7].

The aim of this study was to observe the tooth loss over age in a sample of low income Brazilian patients and analyze their ability to chew, relating it to how much the lost of oral function impact over OHRQoL.

\section{Materials and Methods}

This is a single center, observational study. It was submitted and approved in the University Ethical Committee for Human Research and all participants signed an informed consent form before information collection. The data were collected among June 2010 to June 2011.

\section{Clinical questionnaire and clinical examination}

The questionnaire included questions to obtain basic socio demographic information (gender, age, working activity, etc.), habits and the oral clinical condition. The socio demographic questions were applied by the researcher and answered by the subject. The clinical examination was performed by trained and calibrated dental students enrolled in the study and it was performed in consulting room with potent illumination and under direct supervision by the principal researcher, who was able to resolve any doubts. Dental mouth mirror and dental and periodontal probe were used. Additional X-ray image was taken whenever necessary.

A natural teeth were defined as a tooth with the ability to chew or functional with or without dental restoration (amalgam or composite), but teeth with fixed prosthesis or dental implants were not considered. Exodontia indicated was defined as the situations where tooth cannot be recovered due to any condition and exclude intact third molars surgeries.

\section{Chew's ability}

The ability to chew was measured by the index of chewing ability (ICA) developed by Leake [8]. The ICA is a very simple, five-item yes/ no questions based in the ability of chew foods like, boiled vegetables, salads, raw carrots/ celery, steaks or chops and fresh apples, in a crescent difficulty to chew. The answers generate a 0-5 index-score (no $=0$ and

*Corresponding author: Marcelo Carlos Bortoluzzi, University of the West of Santa Catarina, Faculty of Dentistry, Av Getúlio Vargas 2125, Flower Bairro da Serra, Joaçaba, Santa Catarina/ Brazil, South America 89600-000, Tel: +554935512047 E-mail: mbortoluzzi@gmail.com, marcelo.bortoluzzi@unoesc.edu.br

Received October 09, 2012; Accepted November 17, 2012; Published November 19, 2012

Citation: Bortoluzzi MC, Traebert J, Lasta R, da Rosa TN, Capella DL (2013) Tooth Loss, Chewing Ability and Quality of Life. A Comparative Study. Dentistry 3:152. doi:10.4172/2161-1122.1000152

Copyright: () 2013 Bortoluzzi MC, et al. This is an open-access article distributed under the terms of the Creative Commons Attribution License, which permits unrestricted use, distribution, and reproduction in any medium, provided the original author and source are credited. 
yes $=1$ ), meaning that if you are able to chew all the five items you have a competent ability to chew and a single "no" put you in the disability group. So, to conduct the analysis the responders were assigned to one of two categories: (a) those with chewing competence, scoring 5 on the index and, (b) those deficient in chewing ability, scoring $0-4$ on the index.

\section{OHIP-14}

The Oral Health Impact Profile (OHIP) was developed by Slade and Spencer [2] and later a shortened version of the OHIP was validated (OHIP-14) [3]. The Portuguese version of the OHIP-14, was adapted to the Brazilian-Portuguese language and culture by Almeida et al. [9]. The questionnaire was conceived to measure how different oral conditions affect quality of life in an overall sense. It is organized into 14 questions or items distributed into seven conceptual impact dimensions (two items within each of the seven dimensions): "functional limitations", "physical pain", "psychological discomfort", "physical disability", "psychological disability", "social disability" and "handicap". The answers were assessed using a Likert type evaluation scale with 5 points: never $=0$; rarely $=1$; sometimes $=2$; repeatedly $=3$; always $=4$. The impact over the quality of life can be measurable through sum of the ordinal values of the 14 items and/or summoning the two items within each of the seven dimensions. Higher scores indicate a worse oral health-related quality of life state.

\section{Results}

The sample was composed by 171 random volunteers that searched dental treatment in the Dental School of University of the West of Santa Catarina. Female patient comprised $54.4 \%$ (93) of the sample. Mean age was 47 (SD 15.2). The sample was composed by low income families and daily activities most cited were housekeeping, small propriety farming, bricklayer's mate and general services.

Periodontal disease was present in 39 (22.8\%) patients, while active tooth decay was observed in 67 (39.2\%) subjects and $36(21.1 \%)$ patients had, at least, one tooth with exodontia indicated. The number of natural teeth in mouth ranged from 0 to 32, mean of 13.3 (SD 10.6). The mean number of natural teeth in mouth according the age group (in years - y) observed was: 16-20 (y), 27.1; 21-30 (y), 24.2; 31-40 (y), 21.5; 41-50 (y), 12.5; 51-60 (y), 10.4; 61-70 (y), 3.6; $71(\mathrm{y})$ or more (Figure 1). Table 1 describes the clinical situation and functionality of the maxilla and mandible.

The results about quality of life and chew's ability evaluated by the Index of Chewing Ability (ICA) and OHIP-14 can be viewed in tables 2 and 3 respectively. Chew disability showed a negative impact over the QoL (overall OHIP) and in 5 of 7 OHIP domains. The impact of ICA over the quality of life can be viewed in table 4 .

The analysis also showed a negative correlation between the number of natural teeth in mouth and the total scores of the OHIP-14 (Spearman's rho correlation coefficient -.26, $\mathrm{P}=.001,2$-tailed), and this is interpreted as lower number of natural teeth, higher the scores of OHIP-14 or poorer quality of life. These results can be viewed in the scatter-dot distribution graph (Figure 2). The number of natural teeth also decrease with the increase of the age (Spearman's rho correlation coefficient -.7, $\mathrm{P}<.001,2$-tailed) and, as expected, low number of natural teeth was also associated with chew disability (ICA: chew's ability versus disability) (Mann-Whitney $\mathrm{U}-\mathrm{Test}, \mathrm{P}<.001$ ). Consequently, age in this sample, over than 40 years, was also associated with chew disability (Pearson Chi-Square $\mathrm{P}<.001$ ) and poorer quality of life (Mann-Whitney $\mathrm{U}$ test $\mathrm{P}=.01$ ).

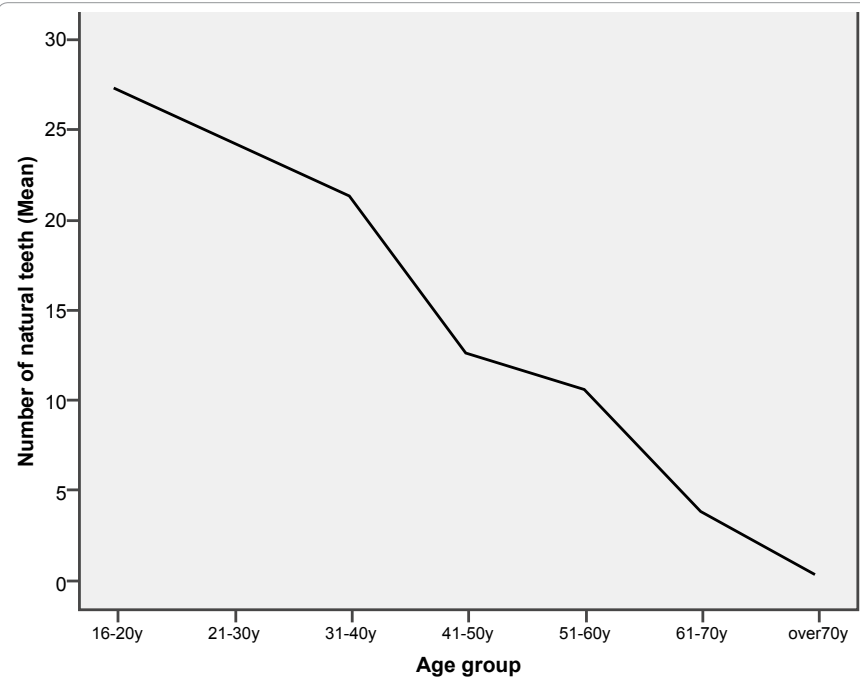

Figure 1: Graph showing the gradual and constant (mean) decrease of natural teeth in mouth according to age group (years).

\begin{tabular}{|c|c|c|c|c|}
\hline $\begin{array}{l}\text { Oral Function Clinical } \\
\text { Situation }\end{array}$ & Maxilla & & Mandible & \\
\hline & $\begin{array}{l}\text { Frequency } \\
\text { (\%) }\end{array}$ & $\begin{array}{l}\text { Cumulative } \\
\text { Percent }\end{array}$ & Frequency & $\begin{array}{l}\text { Cumulative } \\
\text { Percent }\end{array}$ \\
\hline $\begin{array}{l}\text { Edentate total without } \\
\text { prosthesis }\end{array}$ & $3(18)$ & 1.8 & $7(4.1)$ & 4.1 \\
\hline $\begin{array}{l}\text { Edentate total with } \\
\text { prosthesis }\end{array}$ & 75 (43.9) & 45.6 & $26(15.2)$ & 19.3 \\
\hline $\begin{array}{l}\text { Edentate partial without } \\
\text { prosthesis }\end{array}$ & $11(6.4)$ & 52.0 & $56(32.7)$ & 52.0 \\
\hline $\begin{array}{l}\text { Edentate partial with } \\
\text { removable prosthesis }\end{array}$ & $25(14.6)$ & 66.7 & $20(11.7)$ & 63.7 \\
\hline $\begin{array}{l}\text { Edentate partial with } \\
\text { fixed prosthesis (dental } \\
\text { implants, conventional fixed } \\
\text { prosthesis, but still missing } \\
\text { teeth) }\end{array}$ & $1(.6)$ & 67.3 & $0(0)$ & 63.7 \\
\hline $\begin{array}{l}\text { Oral function preserved } \\
\text { due the presence of the } \\
\text { majority of the teeth (and/or } \\
\text { few fixed prosthesis) }\end{array}$ & $28(16.4)$ & 83.6 & $37(21.6)$ & 85.4 \\
\hline $\begin{array}{l}\text { Oral function preserved due } \\
\text { the presence of all teeth } \\
\text { (excluding third molars) }\end{array}$ & $28(16.4)$ & 100.0 & $25(14.6)$ & 100.0 \\
\hline Total & $171(100)$ & & $171(100)$ & \\
\hline
\end{tabular}

Table 1: Clinical situation and functionality of the maxilla and mandible.

\section{Discussion}

Brazil has a long and sad history about poor quality of oral health which renders internally the title of "edentates' country", besides the good technical and educational quality and an elevate number of dental schools (around 200). Brazil has actually around 216.000 dentists in activity but it does not seem to ameliorate the oral conditions of the Brazilians. Worse, no news about serious federal preventive dental policy to change this scenario and, as we observed in this study, patients as young as 40 years, still suffer with loss of teeth with consequent chew's disability and impairment of quality of life, similar to what was found by Silva et al. [10]. A study conducted in Taiwan by Hsu et al. [7] observed as well that the increase of age also increase the number of tooth loss. That study concluded that the number of healthy remaining 


\begin{tabular}{|l|c|c|c|c|}
\hline Most difficult food chewed & Score & Item Frequency & Percent & Chewing ability (\%) \\
\hline None & 0 & 2 & 1.2 & \\
\hline Boiled vegetables & 1 & 15 & 8.8 & \\
\hline Salads & 2 & 29 & 17.0 & Disability (59.6\%) \\
\hline Raw carrots/ celery & 3 & 32 & 18.7 & \\
\hline Steaks or chops & 4 & 24 & 14.0 & \\
\hline Apples & 5 & 69 & 40.4 & $\begin{array}{c}\text { Competent } \\
(40.4 \%)\end{array}$ \\
\hline & Total & 171 & 100.0 & \\
\hline
\end{tabular}

Table 2: Distribution of the Chewing Ability Index (ICA) and the characterization of its scores into chewing competence and chewing disability.

\begin{tabular}{|l|r|r|r|r|r|}
\hline $\begin{array}{l}\text { OHIP domains and total } \\
\text { scores (1) }\end{array}$ & Range & Minimum & Maximum & Mean & $\begin{array}{c}\text { Std. } \\
\text { Deviation }\end{array}$ \\
\hline Functional limitation & $0-8$ & 0 & 7 & .7 & 1.2 \\
\hline Physical pain & $0-8$ & 0 & 8 & 2.1 & 2.0 \\
\hline Psychological discomfort & $0-8$ & 0 & 8 & 2.6 & 2.6 \\
\hline Physical disability & $0-8$ & 0 & 8 & 1.4 & 2.1 \\
\hline Psychological disability & $0-8$ & 0 & 8 & 1.4 & 1.8 \\
\hline Social disability & $0-8$ & 0 & 8 & .9 & 1.5 \\
\hline Handicap & $0-8$ & 0 & 8 & .5 & 1.4 \\
\hline OHIP Total Scores & $0-56$ & 0 & 47 & 9.9 & 8.9 \\
\hline
\end{tabular}

(1) OHIP-14: higher score indicates poorer quality of life

Table 3: Scores of the Oral Health Impact Profile (OHIP) questionnaire according to its domains and total scores.

\begin{tabular}{|l|r|r|l|}
\hline $\begin{array}{l}\text { OHIP domains and total } \\
\text { scores (1) }\end{array}$ & \multicolumn{2}{|c|}{ Chewing ability } & $\begin{array}{l}\text { Mann-Whitney } \\
\text { U Test (CI95\%) }\end{array}$ \\
\hline OHIP Mean scores & 1.02 & $\begin{array}{c}\text { Competent } \\
\text { OHIP Mean } \\
\text { scores }\end{array}$ & \\
\hline Functional limitation & 2.67 & .43 & $\mathrm{P}=.002$ \\
\hline Physical pain & 3.02 & 1.45 & $\mathrm{P}<.001$ \\
\hline Psychological discomfort & 1.93 & 2.03 & $\mathrm{P}=.018$ \\
\hline Physical disability & 1.82 & .61 & $\mathrm{P}<.001$ \\
\hline Psychological disability & 1.07 & .77 & $\mathrm{P}<.001$ \\
\hline Social disability & .75 & .77 & $\mathrm{P}=.45$ \\
\hline Handicap & 12.28 & .35 & $\mathrm{P}=.12$ \\
\hline OHIP Total Scores & 6.41 & $\mathrm{P}<.001$ \\
\hline
\end{tabular}

(1) OHIP-14: higher score indicates poorer quality of life

Table 4: The impact of the Index of Chewing Ability classified into two categories, chewing competence and chewing disability, over the quality of life measured by the Oral Health Impact Profile (OHIP-14) questionnaire.

teeth, including natural teeth and fixed prostheses are key factors in chewing ability.

Besides this study has not an epidemiological design, our sample of patients showed a very concerning situation about losing teeth and its impact over chew ability and quality of life, mainly if we compare these lost of natural teeth with those of the Swedish population which showed at the age of 70 years old an average of 20.7 natural teeth [11]. We also must take into consideration that the present study included, with no exception, low income families and this highlight also the socioeconomic influence over oral health conditions for Brazilians. To our experience [12] is very common allegation for the patient to ask for tooth extraction since they could not afford for endodontic and prosthesis.

According to Preshaw et al. [13] teeth are extracted as a consequence of oral disease, the interaction between the patient and dentist, the dentist's ability to provide care that will sustain a tooth in function, and the patient's preferences. The patient's decisions are likely to be influenced by variables such as the strategic location of the tooth, the importance they place on retaining teeth, their ability (and willingness) to pay for the necessary care that is required if a tooth can be saved, their willingness to undergo treatment, and the availability of specialist care to resolve complex issues.

Chew's ability may also have influence in dietary preferences and this may contribute for the patients' nutritional status, however this is a matter of discussion since masticatory ability and efficiency are not the only factors affecting nutrition $[14,15]$.

Other studies have confirmed the association between prosthetic status/tooth loss and impair of the quality of life measured by different instruments $[4,16,17]$. Related to the oral health status in older patients, Wostmann et al. [15] did not observe a significant improvement in quality of life (OHIP-G14) after improvement of their oral condition, and that may indicate that quality of life may be permanently worsened after losing teeth. Furthermore, Preshaw et al. [13] declared that the use of removable partial dentures increase plaque and gingivitis and increase the risk for caries, particularly root caries. However, Nickenig et al. [6] observed that, for partially edentulous patients, implant therapy had a positive effect on the OHRQoL (OHIP-G21), nevertheless the scores of QoL never reach the quality of those fully dentate. The most frequently reported problems for that group of patients (partially edentulous) were difficulty chewing, psychological disappointment related to dental problems and dissatisfaction with appearance due to problems with teeth, mouth, or dentures. As we observed within the subscales or domains of the OHIP-14, psychological discomfort and psychological disability are increased in patients with chew's disability as well as, functional limitation, physical pain and disability (impact in 5 of 7 domains of OHIP-14).

It is difficult to explain why the OHIP-14 domain "social disability"

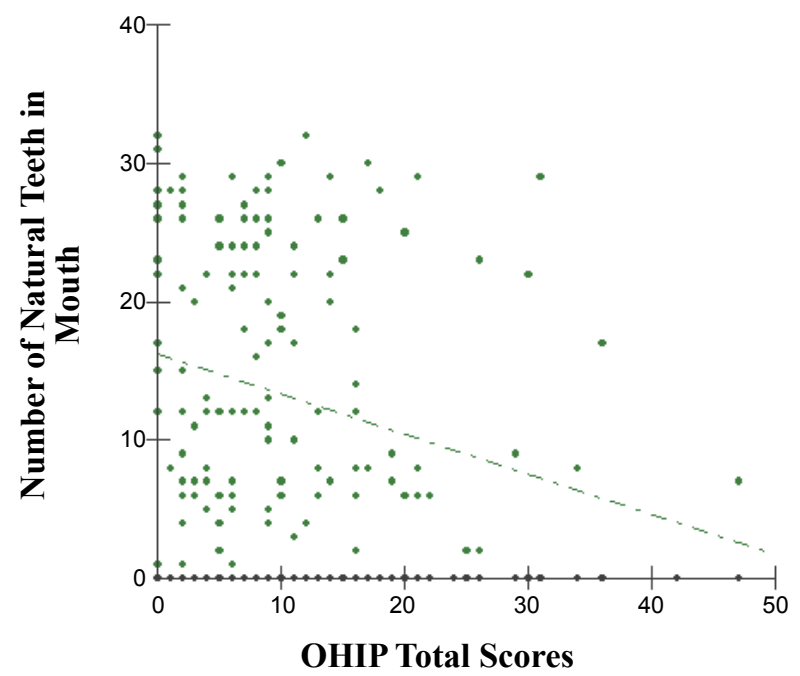

Figure 2: Scatter-dot graph showing that the negative correlation between the number of natural teeth in mouth and the scores of OHIP-14 (Spearman's rho correlation coefficient $-.26, P=.001,2$-tailed). 
Citation: Bortoluzzi MC, Traebert J, Lasta R, da Rosa TN, Capella DL (2013) Tooth Loss, Chewing Ability and Quality of Life. A Comparative Study. Dentistry 3:152. doi:10.4172/2161-1122.1000152

was not affected in chew' disability since the psychological status was. It is possible to speculate that two main reasons may be implicated. The first is the cultural aspect, since Brazilians are described as very sociable people and "his dental problems are quite similar as of his friends, relatives and coworkers" so, no reason to do not socialize. The second is related to complex sample itself, which brings a large age range and a different number of teeth loss, teeth positions, prosthesis condition and presence.

In conclusion, this study observed that the chew's disability measured by the index of chewing ability produce a significant and negative impact over oral-health related quality of life (OHIP-14) and both poor quality of life and chew's disability are related with the decrease of the number of natural teeth, therefore, oral health may influence the quality of life.

\section{References}

1. (1993) Study protocol for the World Health Organization project to develop a Quality of Life assessment instrument (WHOQOL). Qual Life Res 2: 153-159.

2. Slade GD, Spencer AJ (1994) Development and evaluation of the Oral Health Impact Profile. Community Dent Health 11: 3-11.

3. Slade GD (1997) Derivation and validation of a short-form oral health impact profile. Community Dent Oral Epidemiol 25: 284-290.

4. Gerritsen AE, Allen PF, Witter DJ, Bronkhorst EM, Creugers NH (2010) Tooth loss and oral health-related quality of life: a systematic review and metaanalysis. Health Qual Life Outcomes 8: 126.

5. Fontijn-Tekamp FA, Slagter AP, Van Der Bilt A, Van 'T Hof MA, Witter DJ, et al. (2000) Biting and chewing in overdentures, full dentures, and natural dentitions. J Dent Res 79: 1519-1524.

6. Nickenig HJ, Wichmann M, Andreas SK, Eitner S (2008) Oral health-related quality of life in partially edentulous patients: assessments before and after implant therapy. J Craniomaxillofac Surg 36: 477-480.

7. Hsu KJ, Yen YY, Lan SJ, Wu YM, Chen CM, et al. (2011) Relationship between remaining teeth and self-rated chewing ability among population aged 45 years or older in Kaohsiung City, Taiwan. Kaohsiung J Med Sci 27: 457-465.

8. Leake JL (1990) An index of chewing ability. J Public Health Dent 50: 262-267.

9. Almeida A, Loureiro CA, Araujo VE (2004) A cross-cultural study of health values using the instrument OHIP-14 (Oral Health Impact Profile) A simplifiedPart I: cultural and linguistic adaptability. UFES Rev Odontol 6: 6-15.

10. Silva ME, Villaça EL, Magalhães CS, Ferreira EF (2010) Impact of tooth loss in quality of life. Cien Saude Colet 15: 841-850.

11. Hugoson A, Koch G, Göthberg C, Helkimo AN, Lundin SA, et al. (2005) Ora health of individuals aged 3-80 years in Jönköping, Sweden during 30 years (1973-2003). II. Review of clinical and radiographic findings. Swed Dent J 29 : 139-155.

12. Bortoluzzi MC, Manfro R, De Déa BE, Dutra TC (2010) Incidence of dry socket alveolar infection, and postoperative pain following the extraction of erupted teeth. J Contemp Dent Pract 11: E033-E040.

13. Preshaw PM, Walls AW, Jakubovics NS, Moynihan PJ, Jepson NJ, et al. (2011) Association of removable partial denture use with oral and systemic health. J Dent 39: 711-719.

14. Kossioni A, Bellou O (2011) Eating habits in older people in Greece: the role of age, dental status and chewing difficulties. Arch Gerontol Geriatr 52: 197-201.

15. Wöstmann B, Michel K, Brinkert B, Melchheier-Weskott A, Rehmann P, et al (2008) Influence of denture improvement on the nutritional status and quality of life of geriatric patients. J Dent 36: 816-821.

16. John MT (2006) Prosthetic status is related to quality of life. J Evid Based Dent Pract 6: 222-223.

17. Saintrain MV, de Souza EH (2011) Impact of tooth loss on the quality of life Gerodontology 29: e632-636.
Citation: Bortoluzzi MC, Traebert J, Lasta R, da Rosa TN, Capella DL (2013) Tooth Loss, Chewing Ability and Quality of Life. A Comparative Study. Dentistry 3:152. doi:10.4172/2161-1122.1000152 